\title{
Review Article \\ The Multifaceted Aspects of Interstitial Lung Disease in Rheumatoid Arthritis
}

\author{
Lorenzo Cavagna, Sara Monti, Vittorio Grosso, Nicola Boffini, Eva Scorletti, \\ Gloria Crepaldi, and Roberto Caporali
}

Division of Rheumatology, University and IRCCS Foundation Policlinico S. Matteo, Viale Golgi 3, 27100 Pavia, Italy

Correspondence should be addressed to Lorenzo Cavagna; lorenzo.cavagna@unipv.it

Received 21 May 2013; Revised 15 August 2013; Accepted 20 August 2013

Academic Editor: Carlo Jose Freire de Oliveira

Copyright (C) 2013 Lorenzo Cavagna et al. This is an open access article distributed under the Creative Commons Attribution License, which permits unrestricted use, distribution, and reproduction in any medium, provided the original work is properly cited.

\begin{abstract}
Interstitial lung disease (ILD) is a relevant extra-articular manifestation of rheumatoid arthritis (RA) that may occur either in early stages or as a complication of long-standing disease. RA related ILD (RA-ILD) significantly influences the quoad vitam prognosis of these patients. Several histopathological patterns of RA-ILD have been described: usual interstitial pneumonia (UIP) is the most frequent one, followed by nonspecific interstitial pneumonia (NSIP); other patterns are less commonly observed. Several factors have been associated with an increased risk of developing RA-ILD. The genetic background plays a fundamental but not sufficient role; smoking is an independent predictor of ILD, and a correlation with the presence of rheumatoid factor and anti-cyclic citrullinated peptide antibodies has also been reported. Moreover, both exnovo occurrence and progression of ILD have been related to drug therapies that are commonly prescribed in RA, such as methotrexate, leflunomide, anti-TNF alpha agents, and rituximab. A greater understanding of the disease process is necessary in order to improve the therapeutic approach to ILD and RA itself and to reduce the burden of this severe extra-articular manifestation.
\end{abstract}

\section{Introduction}

Rheumatoid arthritis (RA) is a chronic, inflammatory condition that mainly affects joints, in terms of pain, erosion, disability, and reduced survival [1-5]. RA may be complicated by several extra-articular manifestations (EAMs) [6-8]. The lung is among the most important targets of EAMs; the spectrum of lung involvement in RA includes manifestations such as pleural disease, rheumatoid nodules, Caplan's syndrome, bronchiectasis $[9,10]$ and, in particular, interstitial lung disease (ILD) [11-14]. The first report of a correlation between pulmonary fibrosis and RA was published in 1948 by Ellman and Ball [11], describing three patients with polyarthritis and interstitial pneumonitis with chronic fibrosing aspects on autopsy. Since this first description as a "curious chronic fibrosing bronchopneumonic lesion," it has become clear that RA associated interstitial lung disease (RA-ILD) actually includes a broad spectrum of disorders that vary greatly in their clinical presentation, pathology, and prognosis [9]. In the following years several authors pointed out the relevance of RA-ILD $[15,16]$, now widely accepted as an extra-articular complication with deep impact on prognosis and on therapeutic approach to RA [17-19]. Several histopathological patterns of ILD have been described [17] and differential diagnosis may be troublesome [20]. The etiopathogenesis of RA-ILD is not completely understood although genetic $[21,22]$, humoral [23], and environmental [24] factors seem to be involved. The picture is further complicated by the possible ILD-promoting effect of several drugs used to treat RA such as DMARDs (e.g., methotrexate and leflunomide) $[25,26]$ and biological agents (e.g., anti-TNF alpha and rituximab) $[27,28]$. In this review we evaluated the main clinical characteristics of RA-ILD, the possible mechanisms underlying the occurrence of this EAM, and the current therapeutic approach.

\section{Epidemiology and Prognosis}

There is a great variation in the estimates of occurrence and in the general aspects associated with RA-ILD; this is partly due to the lack of acknowledged terminology and validated 
TABLE 1: Histologic and clinical classification of IIPs, applicable to RA-ILD (adapted from [29-31]).

\begin{tabular}{ll}
\hline Histologic patterns & Clinical-radiological-pathologic diagnosis \\
\hline Usual interstitial pneumonia (UIP) & (Idiopathic) pulmonary fibrosis/(cryptogenic) fibrosing alveolitis (IPF/CFA) \\
Nonspecific interstitial pneumonia (NSIP) & $\begin{array}{l}\text { Nonspecific interstitial pneumonia (NSIP) } \\
\text { Organizing pneumonia (preferred definition) }=\text { Bronchiolitis obliterans } \\
\text { organizing pneumonia (OP = BOOP) }\end{array}$ \\
Organizing pneumonia (OP) & $\begin{array}{l}\text { Acute interstitial pneumonia (AIP) } \\
\text { Riffuse alveolar damage (DAD) }\end{array}$ \\
Respiratory bronchiolitis (RB) & $\begin{array}{l}\text { Desquamative interstitial pneumonia (DIP) } \\
\text { Lesquamative interstitial pneumonia (DIP) }\end{array}$ \\
Lymphoid interstitial pneumonia (LIP) & Lymoid interstitial pneumonia (LIP)
\end{tabular}

classification criteria, and to the different means of detection employed to diagnose ILD. In 2002, the American Thoracic Society and European Respiratory Society (ATS/ERS) redefined the nomenclature now used for acute and chronic diffuse parenchymal lung diseases [29]. Because of the lack of a dedicated classification, the consensus classification for idiopathic interstitial pneumonias (IIPs) has been adopted to define RA-ILD [30, 31]. RA-ILD can present as any of the seven idiopathic interstitial pneumonias according to the ATS/ERS consensus classification. Usual interstitial pneumonia (UIP) and nonspecific interstitial pneumonia (NSIP) are the main patterns of ILD described in RA although also other forms, including lymphocytic interstitial pneumonia (LIP) and organizing pneumonia (OP), have been less commonly observed $[14,31,32]$. In Table 1 we summarized the different patterns of ILD that may be detected in RA.

The predominance of UIP distinguishes RA from the majority of other connective tissue diseases (CTDs), usually characterized by a prevalence of NSIP pattern [20, 33] although a bias related to diagnostic methodologies is possible. Diagnostic accuracy of high resolution computed tomography (HRCT) for UIP and NSIP with respect to histological diagnosis has been reported to be approximately $70 \%$ in various studies, with possible discordance in up to one-third of cases [34]. Despite these limits, the estimates of RA-ILD prevalence likely fall in the range from $4 \%$ to $30 \%$ $[6,14,35]$, depending on detection methods and selection criteria, and the incidence may be as high as 4.1 per 1,000 people with RA [17].

Although RA is predominant in females, RA-ILD is frequently described in males $[9,10,19,31]$, with a $2: 1$ male to female ratio [10]. It is interesting to observe that even if the incidence of severe EAMs, such as vasculitis, has decreased in the last decades, fewer changes have been observed for ILD [36, 37]. ILD is frequently an early and asymptomatic finding in RA; in a recent study up to $27 \%$ of patients had HRCT findings of ILD within 2 years from disease onset [38], whereas in another study $25 \%$ of RA patients had ILD already diagnosed at presentation and another 25\% developed ILD within 3 years from disease onset [17].

RA-ILD is a significant cause of mortality, with a median survival of 2.6 years versus 9.9 years of RA patients without ILD. The standardized mortality ratio for RA-ILD compared to RA alone is 2.86 [19]. The increased mortality in RA-ILD is mainly due to ILD progression with respiratory failure and direct RA complications [39]. Infectious processes, lung cancer, pulmonary embolisms, and other non-ILD pulmonary conditions, although reported in the setting of RA-ILD [40], are not so relevant on mortality rates as theoretically conceivable [39]. The literature data show that ILD contributes approximately to $6-13 \%$ of the excess mortality of RA patients when compared to the general population $[19,39,41]$, being one of the most significant causes of death in these patients, together with cardiovascular complications [7, 42].

Despite these data, ILD associated with collagen vascular diseases, including RA, was reported to have a better prognosis than the idiopathic type of ILD $[9,31]$, even in cases of RA patients with biopsy proven UIP [42]. A median survival of 60 months in RA-ILD compared with 27 months in IPF has been reported [13]. However, this latter point is a matter of debate; according to different authors the prognosis of RAUIP patients does not differ from that of IPF [11]. Possible factors responsible for these contradictory results could be the occurrence of subtle histologic differences not detectable by conventional radiographic techniques but influencing the correct diagnosis [34], the positive or detrimental influence of immunosuppressive therapies used in the treatment of $\mathrm{RA}$, and the systemic consequences of a chronic autoimmune disease such as RA. Differences in prognosis among RA-ILD patients with different patterns of pulmonary involvement have also been described. Several studies have suggested a relationship of the UIP pattern to a shorter survival particularly when compared to NSIP [10].

\section{Risk Factors}

Several environmental, serologic, clinical, and genetic factors have been associated with the occurrence of RA-ILD. Occupational exposure to inhaled pollutants such as silica may lead to chronic lung inflammation and to the development of various autoimmune diseases such as RA [43]. In established RA, however, silica exposure is associated with the so called "Caplan's syndrome," first described in the early fifties [44]; this is a peculiar syndrome characterized by the occurrence of multiple well-defined rounded nodules on chest X-ray, of various diameters, distributed throughout the lungs but predominantly at the lung periphery $[44,45]$. Lesions appear often in crops may coalesce and form a larger confluent nodule that often may cavitate or calcify $[44,45]$. In subjects not affected by RA, silica exposure is associated with a large 
amount of pathological lung conditions, such as pneumoconiosis, a peculiar form of interstitial lung disease that may lead to progressive massive fibrosis; exposure to silica and coal mine dusts may also result in pulmonary scarring in a pattern that mimics idiopathic pulmonary fibrosis [46]. To date, the pathogenetic link between exposure to silica, pneumoconiosis, Caplan's syndrome, and RA has not been clarified conclusively.

Smoking represents an independent risk factor for the occurrence of both autoantibody-positive $[47,48]$ and -negative RA [48]. The correlation is particularly evident for heavy ( $\geq 10$ pack-years) and currently smoking individuals $[48,49]$. Smoking is associated with several lung morbidities, including ILD [50-52]. The association with smoking is particularly evident for the UIP pattern $[30,53-$ 55]. However, in a recent study involving $356 \mathrm{RA}$ patients with lung involvement (either ILD or airway disease), the strong association between smoking history and ILD observed in the univariate analysis was not confirmed in the multinomial logistic regression analysis, thus suggesting that factors other than smoking may trigger ILD occurrence in RA [23]. According to this study, possible risk factors for RA-ILD are high titers of rheumatoid factor (RF), and to a lesser extent, anticyclic citrullinated peptide antibodies (ACPA), carriage of HLA-DRB1 ${ }^{*} 1502$, and older age [23]. The association of an increased risk of RA-ILD in RF positive patients has been confirmed by other studies $[38,56]$. Data regarding the effect of ACPA on the development of lung disease are contradictory, with some authors confirming the association $[57,58]$ and others denying a possible role in the development of RAILD [59]. It is interesting to observe that both RF and ACPA can be present in smokers with ILD without clinical evidence of RA $[60,61]$. Furthermore citrullination processes have been observed in lung tissue obtained from RA-ILD [62], and peculiar isoforms of citrullinated peptides, as, for example, the Hsp90 Isoforms [63], may be important antigen targets in RA-ILD. The increased citrullination of proteins and peptides in the lung is potentially smoke related due to peptidylarginine deiminase (PAD) increased activity and seems to play a role not only in ILD but also in RA occurrence [64]. The association with an allele connected with RA-ILD development, but not with occurrence of RA itself, HLA-DRB1*1502 has been reported in a different study [65]. As recently described, RA patients carrying DR2 serology (HLADRB1*15 and 16 alleles) and DQB1* 06 have an increased risk of ILD, whereas HLA-DRB1 Shared Epitope (SE) appears to be protective against ILD development [66]. The protective role of HLADRB1 SE is indeed an unexpected finding, being generally associated with an increased risk of severe EAMs in RA $[67,68]$. It should be underlined that these results have been observed in Japanese patients in whom the HLA allelic distribution is quite different from that of other ethnicities; therefore, these associations $[23,65,66]$ should be confirmed by further studies. Older age has also been reported as a possible risk factor for the development of ILD [17, 19, 23]. Koduri et al. reported that risk estimates calculated on a 10 -year difference in age are associated with a $64 \%$ increase in the likelihood of a RA patient of developing ILD over a shorter period of time [17]. Similar results were obtained by Bongartz et al. [19] and by Mori et al. [23]. Although the reason for this association is not completely clear, it is probably related to the established evidence of an increased incidence of EAMs in older RA patients ( $\geq 60$ years) compared to younger ones $[36,69,70]$.

Other risk factors associated with RA-ILD have been reported: high RA disease activity (e.g., DAS28 score) $[19,38]$, high grade functional impairment (measured using health assessment questionnaire) [17], and the presence of articular erosions and rheumatoid nodules [19].

\section{DMARDs and Biological Agents Related ILD}

In clinical practice, one of the most controversial issues is the possibility of ILD-promoting effects of some RA therapeutics. In fact, drugs such as methotrexate (MTX), leflunomide (LEF), antitumor necrosis factors (TNF) alpha agents, and rituximab have been associated with ILD occurrence or progression.

MTX may cause ILD/pneumonitis in $0.86 \%-6.9 \%$ of patients with morbidity and mortality rates reaching $20 \%$ [71]. As recently reported, this side effect may be triggered by genetic factors; HLA-A*31:01 allele has been reported to be a possible predictor of MTX induced ILD in Japanese patients [72]. This particular genetic subset is more common in Japanese population compared to the Caucasian one $(8.7 \%$ versus $3.9 \%$ ), possibly explaining the increased risk of this drug side effect in Japan [73]. Even if environmental factors may be involved [74], hypersensitivity is probably responsible for most cases of pneumonitis associated with MTX, particularly in the case established lung disease [55, 75].

Leflunomide is also associated with ILD [76], with an increased risk in the setting of preexisting lung disease and a potential relevant impact on survival [77, 78]. Similarly to MTX, hypersensitivity reactions may represent the main mechanism of LEF-induced pneumonitis [79]. The development of interstitial fibrosis is possibly connected with the effect of A771726, an active metabolite of LEF that may induce the transition of lung epithelial cells to myofibrasts [80], a phenomenon known as "epithelial-mesenchymal transition" (EMT). EMT is usually involved not only in abnormal wound repair and tissue remodelling, but also in organ fibrosis and reasonably in ILD [81]. However, EMT is not the only pathogenetic mechanisms in LEF-induced ILD. Experimental animal models demonstrated that the administration of LEF alone did not induce the EMT phenotype, but when LEF was administrated in the setting of a profibroting environment, such as bleomycin-induced pulmonary fibrosis, EMT was enhanced. This evidence suggests that the presence of other fibrosis-inducing stimuli, like in the case of preexisting lung fibrosis, may act as important risk factors for the development of LEF-induced ILD [80].

In recent years an increased number of reports described the new-onset or exacerbation of ILD after administration of biologic therapies, in particular anti-TNF alpha agents [8284]. These drugs are pivotal in the treatment of several conditions, in particular RA $[85,86]$. ILD may occur throughout the entire course of therapy with these agents, with reports ranging from few months to several years after treatment 
is introduced, with a mean interval of approximately 26 weeks. A possible correlation with RA-ILD has been reported for all anti-TNF alpha agents approved for the treatment of RA (infliximab, etanercept, adalimumab, certolizumab, and golimumab) $[83,87,88]$. The mechanism of anti-TNFalpha induced ILD is not well established. TNF-alpha is usually considered as a key cytokine in the pathogenesis of interstitial pneumonia [89-91]. Paradoxically, anti-TNF agents may actually have profibrotic effects on the lung. In fact, TNF-alpha promotes apoptosis of pulmonary inflammatory cells, thereby mediating tissue healing. Anti-TNF-alpha therapies may inhibit these apoptotic processes and promote persistence of inflammatory cells in the lung parenchyma and eventually the development of ILD [92]. Support for this hypothesis originates from experiments on TNF-alpha homozygous knockout mice in which intratracheal administration of bleomycin resulted in an accelerated form of pulmonary fibrosis. Exposing these mice to recombinant TNF-alpha effectively reduced inflammation and promoted lung tissue healing [93]. Anti-TNF therapy also promotes the expression of antiinflammatory cytokines, such as TGF$\beta 1$, potentially contributing to profibrotic states [94]. Finally, considering the role of TNF-alpha gene polymorphisms in determing the effectiveness of anti-TNF alpha therapy [95, 96], it is tempting to speculate that a similar mechanism may be involved in the susceptibility to drug-induced ILD, but further studies are needed to confirm this hypothesis.

Anti-TNF induced ILD may present with different patterns of interstitial involvement, most commonly UIP or NSIP; cases of organizing pneumonia, diffuse alveolar damage, and lymphoid interstitial pneumonia have also been described. Complete resolution may be observed in up to $40 \%$ after withdrawal of the biologic agent [83]. Mortality can be as high as $30 \%$ of cases, rising to about $60 \%$ in case of preexisting ILD [83]. Older age ( $>60-65$ years) has been reported as a negative prognostic factor [83, 88]. According to data derived from one European biologics registry, general mortality in RA-ILD does not seem to be different between patients treated with conventional DMARDs or with antiTNF-alpha agents although the proportion of deaths directly attributable to ILD is reported to be higher in this latter group [97]. Further studies on higher numbers of patients are required to confirm these results.

Despite the previously mentioned evidence, the association of anti-TNF alpha treatment and ILD development has been recently questioned. A large study including 8417 patients affected by RA, ankylosing spondylitis, psoriatic arthritis, psoriasis, and inflammatory bowel disease did not show an increased rate of ILD among the 4200 patients treated with anti-TNF agents, compared to those treated with non-biologic therapies, particularly in the RA group (adjusted hazard ratio, 1.03; 95\% CI 0.51-2.07) [98]. Reports also suggest a possible improvement of RA-ILD following treatment with infliximab [99-101] and etanercept $[102,103]$. The peculiar and nonunivocal link between anti-TNF alpha agents and ILD is clearly represented by a patient described by Komiya et al.; in this case report the administration of adalimumab first improved preexisting RA-ILD, and then induced its progression [104].
Finally, also other biological therapies with different mechanisms of action, including rituximab, have been involved in the occurrence of ILD in RA patients [10]. Some authors described the occurrence exnovo of ILD, following rituximab infusion [28]. ILD has also been reported during rituximab therapy for lymphoproliferative disorders [105]. The pathogenetic mechanism is not established. It is possible that by targeting CD20 positive cells, rituximab induces Bcell apoptosis, leading to antigen-presenting-cell maturation, cytotoxic T-cell activation, and subsequent vascular and alveolar damage [106]. In rituximab-ILD cytokine profile shows an increase of proinflammatory molecules such as IL-6 and TNF-alpha, with potential pathogenetic role in promoting interstitial fibrosis [107].

\section{RA-ILD: Potential Pathogenic Cascade}

The pathogenesis of RA-ILD is far from being completely clarified. Several multifactorial components and a large number of risk factors may be involved. Patients' genetic asset could be either predisposing (HLADRB1* $15, \mathrm{HLADRB1}^{*} 16$, $\mathrm{DQB1}^{*} 06[23,66]$, and HLA-A*31:01 [72] alleles, this latter for MTX-related ILD) or protective (HLA-DRB1 SE [66]) for the development of RA-ILD. Environmental factors play a crucial role on a susceptible genetic background. Tobacco use has been recognized as a possible trigger in the development of RA-ILD. Smoking may directly injure respiratory epithelia and vascular endothelial cells $[108,109]$ and stimulate protein citrullination in the lung through local activation of PAD enzymes [64]. Citrullinated proteins may be key elements already at a preclinical level, acting as antigen targets for the local immune response, eventually leading to ACPA formation, RA occurrence [110], and finally lung interstitial involvement, characterized by particularly enhanced citrullination processes $[23,62,63]$. Furthermore, as previously mentioned, smoking may induce RF synthesis [111, 112] that has been associated with an increased risk of RA-ILD by several authors $[19,37,41]$. It is conceivable that smoking may trigger pulmonary immune response through direct lung damage, enhancement of protein citrullination, and autoantibodies synthesis (e.g., RF and ACPA). These events stimulate a local inflammatory response characterized by cellular infiltration and by the release of several mediators that further contribute to tissue damage $[14,113]$. It must be considered that smoking is obviously not the only etiologic agent involved in the development of the disease as demonstrated by the fact that RA and RA-ILD often occur in nonsmokers. This suggests that other environmental [114] or infectious [14] factors are probably involved. Moreover, as analyzed in a previous section, drug-induced ILD is another relevant issue.

Pulmonary cellular infiltrate in RA-ILD is heterogeneous, frequently organized in lymphoid nodular aggregates [115], showing striking similarities with rheumatoid synovium [116]. Follicular B lymphocyte aggregates are mainly peribronchiolar in disposition [117], resembling bronchialassociated lymphoid tissue. These structures are involved in antigen retrieval directly from lung lumen and not through afferent lymphatics as in lymph nodes and are capable of 
mounting adaptive immune responses [117]. Interestingly, an increased number of peribronchiolar B-cell follicles have been correlated with smoking [117], supporting once again not only the possible role of the lung and of environmental factors in promoting RA-ILD, but also RA itself $[64,117]$. Follicular structures are generally accompanied by diffuse infiltration of pulmonary interstitium by plasma cells that may contribute to the humoral immune response through the production of ACPA [117]. These antibodies complex with citrullinated peptides through $\mathrm{Fc}$ receptors expressed on antigen presenting cells, ultimately leading to the production of proinflammatory cytokines, including TNF-alpha [64]. T-lymphocytes are essential to support B-cells activation and differentiation following antigen exposure. An increased $\mathrm{CD} 4+$ and, to a lesser extent, CD3+ T cells infiltrate has been demonstrated in RA-ILD, particularly compared to IIP, independently of the pattern of disease presentation (e.g., RAUIP or RA-NSIP) [118]. Other authors suggested that CD8+ T cells may also be important in the development of pulmonary fibrosis in RA [119]. Although this hypothesis is supported by a report showing that smoking increases the number of CD8+ $\mathrm{T}$ cells in lungs [120], this plausible mechanism of injury should still be elucidated [119]. Furthermore, also neutrophils may be relevant in RA-ILD as suggested by the correlation of bronchoalveolar lavage neutrophilia and evidence of more advanced interstitial fibrosis $[119,121]$. The complexity of lung cellular infiltrates has been confirmed in a recent model of RA-ILD in SKG mice: infiltrating cells observed in this model included CD4+ T cells, B cells, macrophages, and neutrophils [122]. Cytokines and chemokines play a crucial role in the interaction and crosstalk of the cellular network in RA-ILD. TNF-alpha is a key proinflammatory cytokine in the pathogenesis of interstitial lung involvement; it is mainly produced by activated macrophages, lymphocytes, epithelial, and endothelial cells. TNF-alpha plays a central role in the stimulation of cell-cell adhesion and transendothelial migration with a pivotal role in the early phases and in the maintenance of cytokines and chemokines production cascade [123]. TNF-alpha stimulates fibroblasts proliferation promoting their ability to degrade the extracellular matrix $[124]$ and triggering the expression of growth factors such as platelet derived growth factor- $\beta$ (PDGF- $\beta$ ) and transforming growth factor- $\beta$ (TGF- $\beta$ ), cytokines such as interleukin4 (IL-4) and interleukin-13 (IL-13), and chemokines (e.g., CXCL5, CXCL8, CXCL12, and CXCL13) $[14,64,125,126]$ that further contribute to stimulate fibroblast differentiation and proliferation, thus potentially linking inflammatory and fibrotic processes [127]. PDGF- $\beta$ is produced by a wide array of lung cells, including macrophages, fibroblasts, epithelial and endothelial cells, $[127,128]$. PDGF- $\beta$ plays a primary role in the pathogenesis of IPF, figuring among profibrotic and proinflammatory molecules known to be critical in the pathogenesis of ILD, such as TGF-beta and TNF-alpha $[127,129]$. It is interesting to note that the inhibition of PDGF tyrosine kinase receptor significantly attenuates the development of ILD in an experimental mouse model of pulmonary fibrosis [130]. Further studies regarding the role of PDGF in the development of RA-ILD are needed.
TGF-beta is produced by several cell types: macrophages, epithelial, endothelial and dendritic cells, and fibroblasts [127]. The profibrotic action of TGF-beta is mediated by the recruitment and activation of monocytes and fibroblasts, and by the induction of extracellular matrix deposition [127, 131]. TGF-beta also induces fibroblasts' differentiation into myofibroblasts, that represent the main source of extracellular matrix in lung fibrogenetic processes [132]. The role of chemokines (CXCL5, CXCL8, CXCL12, CXCL13) in the recruitment and organization of lung interstitial inflammatory infiltrate in RA-ILD is still largely unknown. These chemokines are secreted by macrophages, fibroblast and epithelial cells and act trough fibroblast recruitment and activation [127]. CXCL13 is a B-cells chemoattractant known to regulate lymphoid follicules organization within rheumatoid synovial tissue [116]. The exact role of this chemokine in the lung parenchima still needs to be clarified although it has been demonstrated that CXCL13 expression correlates with the extent of inducible bronchus-associated lymphoid tissue (iBALT) in patients with RA-ILD. This finding introduces a possible fascinating connection of pathogenetic mechanisms linking arthritis to extra-articular manifestations of RA.

Other mediators involved in this multi-step pathogenic cascade include matrix metalloproteinases, originated from damaged epithelia, that perpetuate this crosstalk between inflammatory and fibrotic processes, by the enhancement of cellular recruitment ( $\mathrm{B}$ and $\mathrm{T}$ cells, macrophages, and neutrophils) and by the production of additional profibrotic mediators. Angiogenesis, induced by vascular endothelial cell growth factor and by the proinflammatory milieu, is also strictly connected with different phases of the pathological processes of inflammation and fibrosis (Figure 1).

\section{RA-ILD Diagnosis}

Although some patients with proven RA-ILD can be asymptomatic, the majority present with exertional dyspnoea and dry cough. Pleuritic chest pain, fever, haemoptysis, and tachypnoea are also common. Bibasal crackles on chest examination are the most frequent finding $[9,31]$.

Plain chest radiography mainly reveals reticular and fine nodular opacities. These findings are usually more concentrated in the lower lung zones. Chest radiography has a low sensitivity for detection of ILD and can be normal in early stages [9]. In the majority of patients pulmonary function tests (PFT) demonstrate a restrictive defect with low forced vital capacity (FVC), low total lung capacity (TLC) with or without low diffusion capacity of the lung for carbon monoxide (DLCO), and hypoxemia at rest or on exertion $[9,31]$. Decreased DLCO has been described in up to $40 \%$ of RA patients without signs or symptoms of lung disease [9] and is reported to be the most sensitive test for predicting the presence of ILD on HRCT [133].

Bronchoalveolar lavage (BAL) is not routinely used as a diagnostic modality in RA-ILD because BAL changes may be seen even in the absence of ILD. BAL characteristics in RA-ILD patients show a predominance of neutrophils and macrophages [31]. The analysis of BAL fluid may not be helpful to distinguish between different subtypes of 


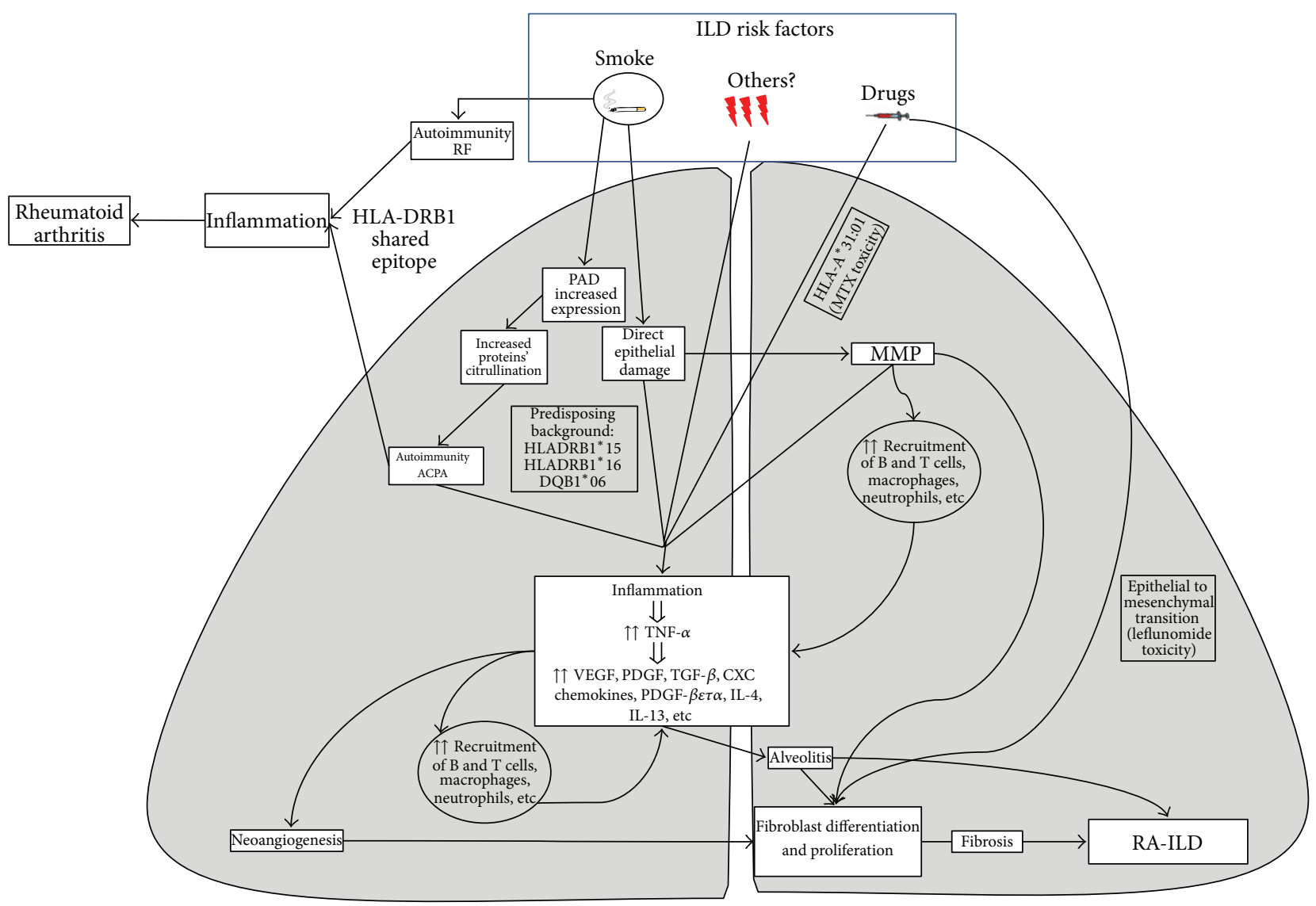

FIGURE 1: Possible pathogenetic mechanisms involved in the occurrence of interstitial lung disease in rheumatoid arthritis. ILD: interstitial lung disease, RF: rheumatoid factor, ACPA: anticyclic citrullinated peptide antibodies, VEGF: vascular endothelial growth factor, PDGF: platelet derived growth factor, PAD: peptidylarginine deiminase, and MTX: methotrexate, MMP: metalloproteinase.

RA-ILD; however, a slightly higher percentage of neutrophils $(>4 \%)$ [134] may be more frequent in UIP. Lymphocytosis $(>18 \%)$ is more common in NSIP and OP [31]. Nevertheless, the results of BAL cellularity may play a prognostic role, with neutrophilia associated with more advanced disease involvement and decreased response to therapy [134, 135]. BAL may also be useful in excluding infectious processes.

HRCT has been accepted as the standard noninvasive method of diagnosing and following ILD in patients with RA [136]. The results of HRCT have been shown to correlate closely with those of open lung biopsy $[13,135]$. The most frequent HRCT findings detected in different subtypes of RAILD are presented in Table 2. High prevalence of enlarged mediastinal lymphnodes in patients with ILD is described [136].

Surgical lung biopsy provides the best means of establishing a histopathological diagnosis. However, because of the potential risks associated with this procedure, many patients are diagnosed without pathological confirmation. Usually, video-assisted thoracoscopic surgery (VATS) is preferred to open-lung biopsy. It is important to note that transbronchial biopsies are not useful in the diagnosis, with the exception of DAD/AIP, and occasionally organizing pneumonia OP/COP
[29]. Histological changes in RA-ILD are very similar to those seen in IPF [9] and are summarized in Table 2.

The individuation of biomarkers to be used in the clinical setting to guide diagnosis and response to treatment is still ongoing. Increasing attention has been paid to a serologic marker of pulmonary disease, KL-6 (Krebs von den Lungen6, a high molecular weight glycoprotein expressed on proliferated type 2 alveolar pneumocytes and epithelial cells), that is known to occur in patients with interstitial pneumonia, hypersensitivity pneumonitis, tuberculosis, sarcoidosis, and pulmonary alveolar proteinosis. It has also been reported that KL-6 is elevated in RA-ILD [30, 137]. KL-6 can be used as a useful marker reflecting the severity of pulmonary fibrosis, the grade of alveolitis, and the extent of HRCT lesions and for detecting active and progressive lung disease in RA-ILD; however, KL-6 may not be very sensible in detecting early stages of lung disease [137]. Oyama et al. [138] demonstrated that KL-6 is elevated in $88.9 \%$ of patients with active ILD and only in $0.6 \%$ of RA patients without active interstitial disease. RA-ILD patients present high levels of proliferative potential colony-forming cells (HPP-CFCs) in peripheral blood compared to those without ILD [139]. High levels of anti-cytokeratin 19 [140], IL-1, anti-IL1 antibodies, and serum 
TABLE 2: Histological and radiological patterns of RA-ILD [9, 10, 29-31].

\begin{tabular}{|c|c|c|c|}
\hline Pattern & Histology & CT features & CT differential diagnosis \\
\hline UIP & $\begin{array}{l}\text { Subpleural and peripheral fibrosis. } \\
\text { Fibroblastic foci, lymphoid aggregates } \\
\text { with germinal centres and honeycombing } \\
\text { are characteristic. Mild inflammation; } \\
\text { architectural destruction. }\end{array}$ & $\begin{array}{l}\text { Peripheral, subpleural, basal reticulation, } \\
\text { and honeycombing } \\
\text { Traction bronchiectasis, architectural } \\
\text { distorsion, GGO (less diffuse). Subpleural } \\
\text { lines }\end{array}$ & $\begin{array}{l}\text { IPF, other collagen vascular diseases, } \\
\text { hypersensitivity pneumonitis } \\
\text { (micronodules and sparing of lung } \\
\text { bases), sarcoidosis, asbestosis (pleural } \\
\text { thickening). }\end{array}$ \\
\hline NSIP & $\begin{array}{l}\text { Uniform interstitial involvement; various } \\
\text { degrees of fibrosis and/or inflammation. } \\
\text { Lymphoid aggregates. Rare } \\
\text { honeycombing }\end{array}$ & $\begin{array}{l}\text { Bilateral, symmetrical, patchy, mainly basal } \\
G G O \text {, possible reticulation, traction } \\
\text { bronchiectasis, irregular lines, or } \\
\text { consolidation. Little or no honeycombing } \\
\text { (in fibrosing NSIP). }\end{array}$ & $\begin{array}{l}\text { UIP, DIP, COP, hypersensitivity } \\
\text { pneumonitis, and HIV-associated } \\
\text { interstitial lung disease. }\end{array}$ \\
\hline OP & $\begin{array}{l}\text { Connective tissue plugs within small } \\
\text { airways and air spaces (Masson bodies). } \\
\text { Little or no inflammation or fibrosis. }\end{array}$ & $\begin{array}{l}\text { Patchy and multiple airspace consolidation, } \\
\text { mainly basal, peripheral, or } \\
\text { peribronchovascular. Air bronchograms can } \\
\text { be seen. Possible associated GGO or } \\
\text { centrilobular nodules. }\end{array}$ & $\begin{array}{l}\text { Infections, vasculitis, sarcoidosis, } \\
\text { alveolar carcinoma, lymphoma, } \\
\text { eosinophilic pneumonia, NSIP, and } \\
\text { COP. }\end{array}$ \\
\hline DAD & $\begin{array}{l}\text { (i) Acute phase: hyaline membranes, } \\
\text { edema. } \\
\text { (ii) Organizing phase: airspace and } \\
\text { interstitial organization }\end{array}$ & $\begin{array}{l}\text { (i) Acute phase: progressive, patchy, or } \\
\text { diffuse GGO and dependent consolidation, } \\
\text { often with lobular sparing } \\
\text { (ii) Organizing phase: reticulation, traction } \\
\text { bronchiectasis, and architectural distorsion. }\end{array}$ & $\begin{array}{l}\text { Hydrostatic edema, pneumonia, } \\
\text { eosinophilic pneumonia, and ARDS } \\
\text { (but more symmetrical and lower lung } \\
\text { zones) }\end{array}$ \\
\hline DIP & $\begin{array}{l}\text { Extensive macrophage accumulation in } \\
\text { the distal air spaces. Mild interstitial } \\
\text { involvement. }\end{array}$ & $\begin{array}{l}\text { Patchy } G G O \text {, basal, and peripheral. } \\
\text { Microcystic changes within GGO, reticular } \\
\text { lines. }\end{array}$ & $\begin{array}{l}\text { RB-ILD, hypersensitivity pneumonitis, } \\
\text { sarcoidosis, and Pneumocystis jiroveci } \\
\text { pneumonia. }\end{array}$ \\
\hline RB-ILD & $\begin{array}{l}\text { Bronchiolocentric macrophage } \\
\text { accumulation. Mild bronchiolar fibrosis }\end{array}$ & $\begin{array}{l}\text { Diffuse/upper lobes distribution, } \\
\text { centrilobular nodules, bronchial wall } \\
\text { thickening, and patchy GGO. }\end{array}$ & $\begin{array}{l}\text { DIP, NSIP, and hypersensitivity } \\
\text { pneumonitis }\end{array}$ \\
\hline LIP & $\begin{array}{l}\text { Bronchiolocentric lymphoid tissue } \\
\text { hyperplasia }\end{array}$ & $\begin{array}{l}\text { Diffuse, GGO, centrilobular nodules, septal } \\
\text { and bronchovascular thickening, } \\
\text { thin-walled cysts, and lymph node } \\
\text { enlargement. }\end{array}$ & $\begin{array}{l}\text { Sarcoidosis, lympangitic carcinoma, } \\
\text { and Langherans' cell histiocytosis }\end{array}$ \\
\hline
\end{tabular}

LDH are reported [141], but their clinical utility still has to be better defined.

\section{Differential Diagnosis}

Differential diagnosis can be very challenging considering that interstitial lung involvement is not exclusive of RA but can be a complication of several conditions in the setting of connective tissue diseases (CTD). Antisynthetase syndrome (ASS) is the prototypical example of these conditions. ASS is characterized by the occurrence of peripheral arthritis, myositis, interstitial lung disease (ILD), typical cutaneous manifestations (e.g., mechanic's hands), and Raynaud's phenomenon, together with the positivity of antisynthetase antibodies $[20,142]$. In these patients, ILD is described in up to $95 \%$ [20]. Arthritis is frequently symmetrical, and joint erosions and ACPA positivity have been described also in ASS patients [143], making the differential diagnosis between RA and ASS particularly challenging. Some reports indicate that the onset of different manifestations may be spread out $[144,145]$ with patients presenting first with arthritis and then with ILD. In our experience on 18 ASS, arthritis was the first symptom in 5 cases; all patients developed ILD in a time interval ranging from 3 months to 13 years.

Opportunistic infections, often connected with immunosuppressive treatments, particularly with biologic therapies, can mimick RA-ILD and can represent a real diagnostic challenge. Differential diagnosis in this setting can be even more troublesome in the case of patients with preexisting ILD [40]. Pathogens to consider as potential ILD mimickers are Pneumocystis jiroveci, fungal [40] and viral infections such as Epstein-Barr [146] and cytomegalovirus [147]. The main differential diagnosis based on radiological aspects is presented in Table 2. From the previously mentioned evidence it is clear that differential diagnosis is fundamental in distinguishing RA-ILD from different conditions that can be great mimickers such as ASS or infectious diseases. This process is fundamental in order to promptly start the appropriate treatment, with significant influence on patients' prognosis $[20,148]$.

\section{RA-ILD Treatment}

To date, little is known about optimal treatment for RA-ILD and whether the pattern of ILD may influence the response to 
immunosuppression [10]. For newly diagnosed patients, firstline treatment is generally based on high dose corticosteroids [149] that may be associated with immunosuppressants such as cyclophosphamide $[14,150]$ and azathioprine $[14,151]$. Mycophenolate mofetil should be considered as a potentially useful treatment, considering its additional action on fibroblasts, endothelial cells, and smooth muscle cells [151, 152]. Similarly to ASS $[20,148]$, good results have been obtained with cyclosporine [153-156]. Despite the previously mentioned lung toxicity, cases of MTX and LEF efficacy in RAILD have been reported [157]. As stated in a previous section, the relationship between anti-TNF alpha agents and ILD is far from being elucidated, and the role of rituximab has been recently questioned after the first reports of drug-induced ILD. Data are scarce regarding other biological therapies such as abatacept or tocilizumab. This latter improved RA-ILD in one single case report [158], whereas other authors addressed ILD occurrence or exacerbation following tocilizumab therapy $[159,160]$.

\section{Conclusions}

Although ILD is a well-established EAM of RA with a substantial impact on prognosis, it is evident that several aspects are far from being fully elucidated and are still widely discussed. In particular, we should clarify the cascade of events underlying the occurrence of ILD, by linking all etiologic and pathogenetic steps, starting from established risk factors (such as smoking) and resulting in the ultimate pulmonary manifestation (lung fibrosis). The comprehension of these passages is mandatory in order to improve the therapeutic approach of RA-ILD and to minimize the risk of ILD development in potentially predisposed patients.

\section{Glossary}

ACPA: Anticyclic citrullinated peptide antibodies

AIP: $\quad$ Acute interstitial pneumonia

ASS: $\quad$ Antisynthetase syndrome

ATS/ERS: American Thoracic Society/European Respiratory Society

BAL: Bronchoalveolar lavage

BOOP: Bronchiolitis obliterans organizing pneumonia (recently classified as OP)

CFA: Cryptogenic fibrosing alveolitis

COP: Cryptogenic organizing pneumonia

CTDs: Connective tissue diseases

DAD: Diffuse alveolar damage

DIP: Desquamative interstitial pneumonia

DLCO: Diffusion capacity of the lung for carbon monoxide

DMARDs: Disease modifying antirheumatic drugs

EAMs: Extra-articular manifestations

EMT: Epithelial-mesenchymal transition

FVC: $\quad$ Forced vital capacity

GGO: $\quad$ Ground glass opacities

HRCT: High resolution computed tomography

IIPs:

$\begin{array}{ll}\text { IL-13: } & \text { Interleukin-13 } \\ \text { IL-4: } & \text { Interleukin-4 } \\ \text { IL-6: } & \text { Interleukin-6 } \\ \text { ILD: } & \text { Interstitial lung disease } \\ \text { IPF: } & \text { Idiopathic pulmonary fibrosis } \\ \text { KL-6: } & \text { Krebs von den Lungen-6 } \\ \text { LEF: } & \text { Leflunomide } \\ \text { LIP: } & \text { Lymphoid interstitial pneumonia } \\ \text { MMP: } & \text { Metalloproteinase } \\ \text { MTX: } & \text { Methotrexate } \\ \text { NSIP: } & \text { NonSpecific Interstitial Pneumonia } \\ \text { OP: } & \text { Organizing pneumonia (preferred } \\ & \text { definition to BOOP) } \\ \text { PAD: } & \text { Peptidylarginine deiminase } \\ \text { PDGF- } \beta \text { : } & \text { Platelet derived growth factor- } \beta \\ \text { PFT: } & \text { Pulmonary function tests } \\ \text { RA: } & \text { Rheumatoid arthritis } \\ \text { RA-ILD: } & \text { Interstitial lung disease in rheumatoid } \\ & \text { arthritis } \\ \text { RB-ILD: } & \text { Respiratory bronchiolitis interstitial lung } \\ & \text { disease } \\ \text { RF: } & \text { Rheumatoid factor } \\ \text { SE: } & \text { Shared epitope } \\ \text { TGF- } \beta \text { : } & \text { Transforming growth factor- } \beta \\ \text { TNF: } & \text { Tumor necrosis factor } \\ \text { TLC: } & \text { Total lung capacity } \\ \text { UIP: } & \text { Usual Interstitial Pneumonia } \\ \text { VEGF: } & \text { Vascular endothelial growth factor. } \\ & \end{array}$

\section{Conflict of Interests}

The authors declare they have no conflict of interest.

\section{References}

[1] C. Montecucco, L. Cavagna, and R. Caporali, "Pain and rheumatology: an overview of the problem," European Journal of Pain Supplements, vol. 3, no. 2, pp. 105-109, 2009.

[2] R. Caporali, L. Cavagna, and C. Montecucco, "Pain in arthritis," European Journal of Pain Supplements, vol. 3, no. 2, pp. 123-127, 2009.

[3] M. Govoni and R. Caporali, "Predicting and managing the progression of structural damage in rheumatoid arthritis: where do we stand?" Clinical and Experimental Rheumatology, vol. 30, no. 4, pp. 459-463, 2012.

[4] E. Krishnan, B. Lingala, B. Bruce, and J. F. Fries, "Disability in rheumatoid arthritis in the era of biological treatments," Annals of the Rheumatic Diseases, vol. 71, no. 2, pp. 213-218, 2012.

[5] S. E. Gabriel, C. S. Crowson, H. M. Kremers et al., "Survival in rheumatoid arthritis: a population-based analysis of trends over 40 years," Arthritis and Rheumatism, vol. 48, no. 1, pp. 54-58, 2003.

[6] M. A. Cimmino, C. Salvarani, P. Macchioni et al., "Extraarticular manifestations in 587 Italian patients with rheumatoid arthritis," Rheumatology International, vol. 19, no. 6, pp. 213-217, 2000.

[7] L. Cavagna, N. Boffini, G. Cagnotto, F. Inverardi, V. Grosso, and R. Caporali, "Atherosclerosis and rheumatoid arthritis: more than a simple association," Mediators of Inflammation, vol. 2012, Article ID 147354, 8 pages, 2012. 
[8] C. Turesson, "Extra-articular rheumatoid arthritis," Current Opinion in Rheumatology, vol. 25, no. 3, pp. 360-366, 2013.

[9] U. A. Gauhar, A. L. Gaffo, and G. S. Alarcón, "Pulmonary manifestations of rheumatoid arthritis," Seminars in Respiratory and Critical Care Medicine, vol. 28, no. 4, pp. 430-440, 2007.

[10] A. de Lauretis, S. Veeraraghavan, and E. Renzoni, "Connective tissue disease-associated interstitial lung disease: how does it differ from IPF? How should the clinical approach differ?" Chronic Respiratory Disease, vol. 8, no. 1, pp. 53-82, 2011.

[11] P. Ellman and R. E. Ball, "Rheumatoid arthritis with joint and pulmonary manifestations," The British Journal of Medicine, vol. 2, no. 4583, pp. 816-820, 1948.

[12] E. H. Rubin, "Pulmonary lesions in "rheumatoid disease" with remarks on diffuse interstitial pulmonary fibrosis," The American Journal of Medicine, vol. 19, no. 4, pp. 569-582, 1955.

[13] E. J. Kim, B. M. Elicker, F. Maldonado et al., "Usual interstitial pneumonia in rheumatoid arthritis-associated interstitial lung disease," European Respiratory Journal, vol. 35, no. 6, pp. 13221328, 2010.

[14] D. P. Ascherman, "Interstitial lung disease in rheumatoid arthritis," Current Rheumatology Reports, vol. 12, no. 5, pp. 363369,2010 .

[15] G. W. Hunninghake and A. S. Fauci, "Pulmonary involvement in the collagen vascular diseases," The American Review of Respiratory Disease, vol. 119, no. 3, pp. 471-503, 1979.

[16] P. Cervantes-Perez, A. H. Toro-Perez, and P. Rodriguez-Jurado, "Pulmonary involvement in rheumatoid arthritis," The Journal of the American Medical Association, vol. 243, no. 17, pp. 1715$1719,1980$.

[17] G. Koduri, S. Norton, A. Young et al., "Interstitial lung disease has a poor prognosis in rheumatoid arthritis: results from an inception cohort," Rheumatology, vol. 49, no. 8, Article ID keq035, pp. 1483-1489, 2010.

[18] A. Young and G. Koduri, "Extra-articular manifestations and complications of rheumatoid arthritis," Best Practice and Research: Clinical Rheumatology, vol. 21, no. 5, pp. 907-927, 2007.

[19] T. Bongartz, C. Nannini, Y. F. Medina-Velasquez et al., "Incidence and mortality of interstitial lung disease in rheumatoid arthritis-a population-based study," Arthritis and Rheumatism, vol. 62, no. 6, pp. 1583-1591, 2010.

[20] L. Cavagna, R. Caporali, L. Abdì-Alì, R. Dore, F. Meloni, and C. Montecucco, "Cyclosporine in anti-Jol-positive patients with corticosteroid-refractory interstitial lung disease," Journal of Rheumatology, vol. 40, no. 4, pp. 484-492, 2013.

[21] L. M. Nogee, A. E. Dunbar, S. E. Wert, F. Askin, A. Hamvas, and J. A. Whitsett, "A mutation in the surfactant protein $\mathrm{C}$ gene associated with familial interstitial lung disease," The New England Journal of Medicine, vol. 344, no. 8, pp. 573-579, 2001.

[22] J. C. Grutters and R. M. du Bois, "Genetics of fibrosing lung diseases," European Respiratory Journal, vol. 25, no. 5, pp. 915927, 2005.

[23] S. Mori, Y. Koga, and M. Sugimoto, "Different risk factors between interstitial lung disease and airway disease in rheumatoid arthritis," Respiratory Medicine, vol. 106, no. 11, pp. 15911599, 2012.

[24] K.G. Saag, S. Kolluri, R. K. Koehnke et al., "Rheumatoid arthritis lung disease. Determinants of radiographic and physiologic abnormalities," Arthritis and Rheumatism, vol. 39, no. 10, pp. 1711-1719, 1996

[25] M. Toyoshima, K. Chida, T. Suda, and M. Sato, "Methotrexate might increase mortality from interstitial lung disease in rheumatoid arthritis," The American Journal of Respiratory and Critical Care Medicine, vol. 185, no. 9, p. 1024, 2012.

[26] S. Inokuma, "Leflunomide-induced interstitial pneumonitis might be a representative of disease-modifying antirheumatic drug-induced lung injury," Expert Opinion on Drug Safety, vol. 10, no. 4, pp. 603-611, 2011.

[27] R. Perez-Alvarez, M. Perez-de-Lis, C. Diaz-Lagares et al., "Interstitial lung disease induced or exacerbated by TNF-targeted therapies: analysis of 122 cases," Seminars in Arthritis and Rheumatism, vol. 41, no. 2, pp. 256-264, 2011.

[28] S. T. Panopoulos and P. P. Sfikakis, "Biological treatments and connective tissue disease associated interstitial lung disease," Current Opinion in Pulmonary Medicine, vol. 17, no. 5, pp. 362367, 2011.

[29] C. Agustí, "American thoracic society/European respiratory society international multidisciplinary consensus classification of the idiopathic interstitial pneumonia," The American Journal of Respiratory and Critical Care Medicine, vol. 165, no. 2, pp. 277304, 2002.

[30] Y. Tsuchiya, N. Takayanagi, H. Sugiura et al., "Lung diseases directly associated with rheumatoid arthritis and their relationship to outcome," European Respiratory Journal, vol. 37, no. 6, pp. 1411-1417, 2011.

[31] H. K. Lee, D. S. Kim, B. Y. Yoo et al., "Histopathologic pattern and clinical features of rheumatoid arthritis-associated interstitial lung disease," Chest, vol. 127, no. 6, pp. 2019-2027, 2005.

[32] Y. C. Manjunatha, A. Seith, H. Kandpal, and C. J. Das, "Rheumatoid arthritis: spectrum of computed tomographic findings in pulmonary diseases," Current Problems in Diagnostic Radiology, vol. 39, no. 6, pp. 235-246, 2010.

[33] M. Gutsche, G. D. Rosen, and J. J. Swigris, "Connective tissue disease-associated interstitial lung disease: a review," Current Respiratory Care Reports, vol. 1, no. 4, pp. 224-232, 2012.

[34] S. N. Mink and B. Maycher, "Comparative manifestations and diagnostic accuracy of high-resolution computed tomography in usual interstitial pneumonia and nonspecific interstitial pneumonia," Current Opinion in Pulmonary Medicine, vol. 18, no. 5, pp. 530-534, 2012.

[35] N. C. Richman, J. Yazdany, J. Graf, V. Chernitskiy, and J. B. Imboden, "Extraarticular manifestations of rheumatoid arthritis in a multiethnic cohort of predominantly Hispanic and Asian patients," Medicine, vol. 92, no. 2, pp. 92-97, 2013.

[36] E. Myasoedova, C. S. Crowson, C. Turesson, S. E. Gabriel, and E. L. Matteson, "Incidence of extraarticular rheumatoid arthritis in olmsted county, Minnesota, in 1995-2007 versus 1985-1994: a population-based study," Journal of Rheumatology, vol. 38, no. 6, pp. 983-989, 2011.

[37] C. M. Bartels, C. L. Bell, K. Shinki, A. Rosenthal, and A. J. Bridges, "Changing trends in serious extra-articular manifestations of rheumatoid arthritis among united state veterans over 20 years," Rheumatology, vol. 49, no. 9, Article ID keq135, pp. 1670-1675, 2010.

[38] H. M. Habib, A. A. Eisa, W. R. Arafat, and M. A. Marie, "Pulmonary involvement in early rheumatoid arthritis patients," Clinical Rheumatology, vol. 30, no. 2, pp. 217-221, 2011.

[39] A. L. Olson, J. J. Swigris, D. B. Sprunger et al., "Rheumatoid arthritis-interstitial lung disease-associated mortality," The American Journal of Respiratory and Critical Care Medicine, vol. 183, no. 3, pp. 372-378, 2011. 
[40] M. J. Hamblin and M. R. Horton, "Rheumatoid arthritisassociated interstitial lung disease: diagnostic dilemma," Pulmonary Medicine, vol. 2011, Article ID 872120, 12 pages, 2011.

[41] A. Young, G. Koduri, M. Batley et al., "Mortality in rheumatoid arthritis. Increased in the early course of disease, in ischaemic heart disease and in pulmonary fibrosis," Rheumatology, vol. 46, no. 2, pp. 350-357, 2007.

[42] E. A. Khan, L. K. Stamp, J. L. O’Donnell, and P. T. Chapman, "Cardiovascular morbidity in rheumatoid arthritis patients in North Canterbury, New Zealand 1999-2008," International Journal of Rheumatic Diseases, vol. 16, no. 1, pp. 19-23, 2013.

[43] P. Stolt, H. Källberg, I. Lundberg, B. Sjögren, L. Klareskog, and L. Alfredsson, "Silica exposure is associated with increased risk of developing rheumatoid arthritis: results from the Swedish EIRA study," Annals of the Rheumatic Diseases, vol. 64, no. 4, pp. 582-586, 2005.

[44] A. Caplan, "Certain unusual radiological appearances in the chest of coal-miners suffering from rheumatoid arthritis," Thorax, vol. 8, no. 1, pp. 29-37, 1953.

[45] J. Schreiber, D. Koschel, J. Kekow, N. Waldburg, A. Goette, and R. Merget, "Rheumatoid pneumoconiosis (Caplan's syndrome)," European Journal of Internal Medicine, vol. 21, no. 3, pp. 168-172, 2010.

[46] R. A. C. Cohen, A. Patel, and F. H. Y. Green, "Lung disease caused by exposure to coal mine and silica dust," Seminars in Respiratory and Critical Care Medicine, vol. 29, no. 6, pp. 651661, 2008

[47] A. Yahya, C. Bengtsson, T. C. Lai et al., "Smoking is associated with an increased risk of developing ACPA-positive but not ACPA-negative rheumatoid arthritis in Asian populations: evidence from the Malaysian MyEIRA case-control study," Modern Rheumatology, vol. 22, no. 4, pp. 524-531, 2012.

[48] T. R. Mikuls, H. Sayles, F. Yu et al., "Associations of cigarette smoking with rheumatoid arthritis in African Americans," Arthritis and Rheumatism, vol. 62, no. 12, pp. 3560-3568, 2010.

[49] D. Hutchinson, L. Shepstone, R. Moots, J. T. Lear, and M. P. Lynch, "Heavy cigarette smoking is strongly associated with rheumatoid arthritis (RA), particularly in patients without a family history of RA," Annals of the Rheumatic Diseases, vol. 60, no. 3, pp. 223-227, 2001.

[50] A. J. Thorley and T. D. Tetley, "Pulmonary epithelium, cigarette smoke, and chronic obstructive pulmonary disease," International Journal of Chronic Obstructive Pulmonary Diseases, vol. 2, no. 4, pp. 409-428, 2007.

[51] B. Balbi, V. Cottin, S. Singh, W. de Wever, F. J. F. Herth, and C. Robalo Cordeiro, "Smoking-related lung diseases: a clinical perspective," European Respiratory Journal, vol. 35, no. 2, pp. 231-233, 2010.

[52] R. Vassallo and J. H. Ryu, "Smoking-related interstitial lung diseases," Clinics in Chest Medicine, vol. 33, no. 1, pp. 165-178, 2012.

[53] M. L. Westedt, J. M. W. Hazes, F. C. Breedveld, P. J. Sterk, and J. H. Dijkman, "Cigarette smoking and pulmonary diffusion defects in rheumatoid arthritis," Rheumatology International, vol. 18, no. 1, pp. 1-4, 1998.

[54] K. G. Saag, S. Kolluri, R. K. Koehnke et al., "Rheumatoid arthritis lung disease: determinants of radiographic and physiologic abnormalities," Arthritis and Rheumatism, vol. 39, no. 10, pp. 1711-1719, 1996.

[55] B. R. Gochuico, N. A. Avila, C. K. Chow et al., "Progressive preclinical interstitial lung disease in rheumatoid arthritis," Archives of Internal Medicine, vol. 168, no. 2, pp. 159-166, 2008.
[56] H. Sakaida, "IgG rheumatoid factor in rheumatoid arthritis with interstitial lung disease," Ryumachi, vol. 35, no. 4, pp. 671-677, 1995.

[57] I. Alexiou, A. Germenis, A. Koutroumpas, A. Kontogianni, K. Theodoridou, and L. I. Sakkas, "Anti-cyclic citrullinated peptide-2 (CCP2) autoantibodies and extra-articular manifestations in Greek patients with rheumatoid arthritis," Clinical Rheumatology, vol. 27, no. 4, pp. 511-513, 2008.

[58] F. Aubart, B. Crestani, P. Nicaise-Roland et al., "High levels of anti-cyclic citrullinated peptide autoantibodies are associated with co-occurrence of pulmonary diseases with rheumatoid arthritis," Journal of Rheumatology, vol. 38, no. 6, pp. 979-982, 2011.

[59] N. Inui, N. Enomoto, T. Suda, Y. Kageyama, H. Watanabe, and K. Chida, "Anti-cyclic citrullinated peptide antibodies in lung diseases associated with rheumatoid arthritis," Clinical Biochemistry, vol. 41, no. 13, pp. 1074-1077, 2008.

[60] A. Fischer, J. J. Solomon, R. M. du Bois et al., "Lung disease with anti-CCP antibodies but not rheumatoid arthritis or connective tissue disease," Respiratory Medicine, vol. 106, no. 7, pp. 1040 1047, 2012.

[61] A. M. Gizinski, M. Mascolo, J. L. Loucks et al., "Rheumatoid arthritis (RA)-specific autoantibodies in patients with interstitial lung disease and absence of clinically apparent articular RA," Clinical Rheumatology, vol. 28, no. 5, pp. 611-613, 2009.

[62] T. Bongartz, T. Cantaert, S. R. Atkins et al., "Citrullination in extra-articular manifestations of rheumatoid arthritis," Rheumatology, vol. 46, no. 1, pp. 70-75, 2007.

[63] L. Harlow, I. O. Rosas, B. R. Gochuico et al., "Identification of citrullinated hsp90 isoforms as novel autoantigens in rheumatoid arthritis-associated interstitial lung disease," Arthritis and Rheumatisms, vol. 65, no. 4, pp. 869-879, 2013.

[64] L. Klareskog, V. Malmström, K. Lundberg, L. Padyukov, and L. Alfredsson, "Smoking, citrullination and genetic variability in the immunopathogenesis of rheumatoid arthritis," Seminars in Immunology, vol. 23, no. 2, pp. 92-98, 2011.

[65] K. Migita, T. Nakamura, T. Koga, and K. Eguchi, "HLA-DRB1 alleles and rheumatoid arthritis-related pulmonary fibrosis," Journal of Rheumatology, vol. 37, no. 1, pp. 205-207, 2010.

[66] H. Furukawa, S. Oka, K. Shimada et al., "Association of human leukocyte antigen with interstitial lung disease in rheumatoid arthritis: a protective role for shared epitope," PLoS ONE, vol. 7, no. 5, Article ID e33133, 2012.

[67] J. D. Gorman, R. F. Lum, J. J. Chen, M. E. Suarez-Almazor, G. Thomson, and L. A. Criswell, "Impact of shared epitope genotype and ethnicity on erosive disease: a meta-analysis of 3,240 rheumatoid arthritis patients," Arthritis and Rheumatism, vol. 50, no. 2, pp. 400-412, 2004.

[68] J. D. Gorman, E. David-Vaudey, M. Pai, R. F. Lum, and L. A. Criswell, "Particular HLA-DRB1 shared epitope genotypes are strongly associated with rheumatoid vasculitis," Arthritis and Rheumatism, vol. 50, no. 11, pp. 3476-3484, 2004.

[69] Y. Santiago-Casas, T. C. González-Rivera, L. E. Castro-Santana et al., "Impact of age on clinical manifestations and outcome in Puerto Ricans with rheumatoid arthritis," Ethnicity and Disease, vol. 20, supplement 1, pp. S1-S191, 2010.

[70] C. Turesson, W. M. O’Fallon, C. S. Crowson, S. E. Gabriel, and E. L. Matteson, "Extra-articular disease manifestations in rheumatoid arthritis: incidence trends and risk factors over 46 years," Annals of the Rheumatic Diseases, vol. 62, no. 8, pp. 722727, 2003. 
[71] V. Saravanan and C. Kelly, "Drug-related pulmonary problems in patients with rheumatoid arthritis," Rheumatology, vol. 45, no. 7, pp. 787-789, 2006.

[72] H. Furukawa, S. Oka, K. Shimada, Rheumatoid ArthritisInterstitial Lung Disease Study Consortium, N. Tsuchiya, and S. Tohma, "HLA-A*31:01 and methotrexate-induced interstitial lung disease in Japanese rheumatoid arthritis patients: a multidrug hypersensitivity marker?" Annals of the Rheumatic Diseases, vol. 72, no. 1, pp. 153-155, 2013.

[73] K. Shidara, D. Hoshi, E. Inoue et al., "Incidence of and risk factors for interstitial pneumonia in patients with rheumatoid arthritis in a large Japanese observational cohort, IORRA," Modern Rheumatology, vol. 20, no. 3, pp. 280-286, 2010.

[74] S. R. Jordan, V. R. Stevanovic, P. Herbison, J. Dockerty, and J. Highton, "Methotrexate pneumonitis in rheumatoid arthritis: increased prevalence with increasing latitude: an epidemiological study of trends in New Zealand," Journal of Clinical Rheumatology, vol. 17, no. 7, pp. 356-357, 2011.

[75] G. J. Carroll, R. Thomas, C. C. Phatouros et al., "Incidence, prevalence and possible risk factors for pneumonitis in patients with rheumatoid arthritis receiving methotrexate," Journal of Rheumatology, vol. 21, no. 1, pp. 51-54, 1994.

[76] J. H. Ju, S. I. Kim, J. H. Lee et al., "Risk of interstitial lung disease associated with leflunomide treatment in Korean patients with rheumatoid arthritis," Arthritis and Rheumatism, vol. 56, no. 6, pp. 2094-2096, 2007.

[77] B. Chikura, S. Lane, and J. K. Dawson, "Clinical expression of leflunomide-induced pneumonitis," Rheumatology, vol. 48, no. 9, pp. 1065-1068, 2009.

[78] T. Sawada, S. Inokuma, T. Sato et al., "Leflunomide-induced interstitial lung disease: prevalence and risk factors in Japanese patients with rheumatoid arthritis," Rheumatology, vol. 48, no. 9, pp. 1069-1072, 2009.

[79] N. Martin, J. A. Innes, C. M. Lambert, C. M. Turnbull, and W. A. H. Wallace, "Hypersensitivity pneumonitis associated with leflunomide therapy," Journal of Rheumatology, vol. 34, no. 9, pp. 1934-1937, 2007.

[80] T. Namba, K.-. Tanaka, Y. Ito et al., "Induction of EMT-like phenotypes by an active metabolite of leflunomide and its contribution to pulmonary fibrosis," Cell Death and Differentiation, vol. 17, no. 12, pp. 1882-1895, 2010.

[81] B. Hinz, S. H. Phan, V. J. Thannickal, A. Galli, M. BochatonPiallat, and G. Gabbiani, "The myofibroblast: one function, multiple origins," The American Journal of Pathology, vol. 170, no. 6, pp. 1807-1816, 2007.

[82] L. Peno-Green, G. Lluberas, T. Kingsley, and S. Brantley, "Lung injury linked to etanercept therapy," Chest, vol. 122, no. 5, pp. 1858-1860, 2002.

[83] R. Perez-Alvarez, M. Perez-de-Lis, C. Diaz-Lagares et al., "Interstitial lung disease induced or exacerbated by TNF-targeted therapies: analysis of 122 cases," Seminars in Arthritis and Rheumatism, vol. 41, no. 2, pp. 256-264, 2011.

[84] F. Pearce, S. R. Johnson, and P. Courtney, "Interstitial lung disease following certolizumab pegol," Rheumatology, vol. 51, no. 3, Article ID ker309, pp. 578-580, 2012.

[85] R. Caporali, F. B. Pallavicini, M. Filippini et al., "Treatment of rheumatoid arthritis with anti-TNF- $\alpha$ agents: a reappraisal," Autoimmunity Reviews, vol. 8, no. 3, pp. 274-280, 2009.

[86] C. Montecucco, R. Caporali, and M. Matucci-Cerinic, "Updating the Italian society for rheumatology recommendations for biologic therapy in adult patients with inflammatory rheumatic diseases," Clinical and experimental rheumatology, vol. 29, no. 3, supplement 66, pp. S3-S6, 2011.

[87] A. Schuller, M. Coudurier, J. C. Lega, C. Khouatra, V. Cottin, and J. F. Cordier, "Interstitial lung disease and anti-TNF- $\alpha$ therapy in rheumatoid arthritis: two different patterns?" Revue des Maladies Respiratoires, vol. 27, no. 3, pp. 232-237, 2010.

[88] S. Mori, F. Imamura, C. Kiyofuji, and M. Sugimoto, "Development of interstitial pneumonia in a rheumatoid arthritis patient treated with infliximab, an anti-tumor necrosis factor $\alpha$-neutralizing antibody," Modern Rheumatology, vol. 16, no. 4, pp. 251-255, 2006.

[89] Q. Ye, H. Dai, R. Sarria, J. Guzman, and U. Costabel, "Increased expression of tumor necrosis factor receptors in cryptogenic organizing pneumonia," Respiratory Medicine, vol. 105, no. 2, pp. 292-297, 2011.

[90] E. M. Thomson, A. Williams, C. L. Yauk, and R. Vincent, "Overexpression of tumor necrosis factor- $\alpha$ in the lungs alters immune response, matrix remodeling, and repair and maintenance pathways," The American Journal of Pathology, vol. 180, no. 4, pp. 1413-1430, 2012.

[91] Y. Mikami, Y. Yamauchi, M. Horie et al., "Tumor necrosis factor superfamily member LIGHT induces epithelial-mesenchymal transition in A549 human alveolar epithelial cells," Biochemical Biophysical Research Communication, vol. 428, no. 4, pp. 451457, 2012.

[92] S. Sen, C. Peltz, K. Jordan, and T. J. Boes, "Infliximab-induced nonspecific interstitial pneumonia," The American Journal of the Medical Sciences, vol. 344, no. 1, pp. 78-78, 2012.

[93] M. Kuroki, Y. Noguchi, M. Shimono et al., "Repression of bleomycin-induced pneumopathy by TNF," Journal of Immunology, vol. 170, no. 1, pp. 567-574, 2003.

[94] T. A. Wynn, "Fibrotic disease and the TH1/TH2 paradigm," Nature Reviews Immunology, vol. 4, no. 8, pp. 583-594, 2004.

[95] M. U. Mirkov, J. Cui, S. H. Vermeulen et al., "Genomenomewide association analysis of anti-TNF drug response in patients with rheumatoid arthritis," Annals of the Rheumatic Diseases, vol. 72, no. 8, pp. 1375-1381, 2013.

[96] F. Ceccarelli, S. D’Alfonso, C. Perricone et al., “The role of eight polymorphisms in three candidate genes in determining the susceptibility, phenotype, and response to anti-TNF therapy in patients with rheumatoid arthritis," Clinical and Experimental Rheumatology, vol. 30, no. 6, pp. 939-942, 2012.

[97] W. G. Dixon, K. L. Hyrich, K. D. Watson, M. Lunt, and D. P. M. Symmons, "Influence of anti-TNF therapy on mortality in patients with rheumatoid arthritis-associated interstitial lung disease: results from the British society for rheumatology biologics register," Annals of the Rheumatic Diseases, vol. 69, no. 6, pp. 1086-1091, 2010.

[98] L. J. Herrinton, L. R. Harrold, L. Liu et al., "Association between anti-TNF- $\alpha$ therapy and interstitial lung disease," Pharmacoepidemiology and Drug Safety, vol. 22, no. 4, pp. 394-402, 2013.

[99] R. Vassallo, E. Matteson, and C. F. Thomas Jr., "Clinical response of rheumatoid arthritis-associated pulmonary fibrosis to tumor necrosis factor- $\alpha$ inhibition," Chest, vol. 122, no. 3, pp. 10931096, 2002.

[100] E. Bargagli, M. Galeazzi, and P. Rottoli, "Infliximab treatment in a patient with rheumatoid arthritis and pulmonary fibrosis," European Respiratory Journal, vol. 24, no. 4, p. 708, 2004.

[101] K. M. Antoniou, M. Mamoulaki, K. Malagari et al., "Infliximab therapy in pulmonary fibrosis associated with collagen vascular disease," Clinical and Experimental Rheumatology, vol. 25, no. 1, pp. 23-28, 2007. 
[102] Y. Wang, S. Q. Xu, J. H. Xu, and C. Ding, “Treatment with etanercept in a patient with rheumatoid arthritis-associated interstitial lung disease," Clinical Medicine Insights: Case Reports, vol. 4, pp. 49-52, 2011.

[103] Y. Horai, T. Miyamura, K. Shimada et al., "Eternacept for the treatment of patients with rheumatoid arthritis and concurrent interstitial lung disease," Journal of Clinical Pharmacy and Therapeutics, vol. 37, no. 1, pp. 117-121, 2012.

[104] K. Komiya, H. Ishii, N. Fujita et al., "Adalimumab-induced interstitial pneumonia with an improvement of pre-existing rheumatoid arthritis-associated lung involvement," Internal Medicine, vol. 50, no. 7, pp. 749-751, 2011.

[105] S. A. Wagner, A. C. Mehta, and D. A. Laber, "Rituximab-induced interstitial lung disease," The American Journal of Hematology, vol. 82, no. 10, pp. 916-919, 2007.

[106] R. Ram, I. Ben-Bassat, O. Shpilberg, A. Polliack, and P. Raanani, "The late adverse events of rituximab therapy-rare but there!," Leukemia and Lymphoma, vol. 50, no. 7, pp. 1083-1095, 2009.

[107] Y. Wu, Y. Jia, J. Xu, X. Shuai, and Y. Wu, "Fatal interstitial lung disease induced by rituximab-containing chemotherapy, treatment with TNF- $\alpha$ antagonist and cytokine profiling: a casereport and review of the literature," Journal of Clinical Pharmacy and Therapeutics, vol. 38, no. 3, pp. 249-253, 2013.

[108] A. J. Thorley and T. D. Tetley, "Pulmonary epithelium, cigarette smoke, and chronic obstructive pulmonary disease," International Journal of Chronic Obstructive Pulmonary Diseases, vol. 2, no. 4, pp. 409-428, 2007.

[109] Q. Yang, M. J. Underwood, M. K. Y. Hsin, X. C. Liu, and G. W. He, "Dysfunction of pulmonary vascular endothelium in chronic obstructive pulmonary disease: basic considerations for future drug development," Current Drug Metabolism, vol. 9, no. 7, pp. 661-667, 2008.

[110] Z. Baka, E. Buzás, and G. Nagy, "Rheumatoid arthritis and smoking: putting the pieces together," Arthritis Research and Therapy, vol. 11, no. 4, p. 238, 2009.

[111] J. D. Mathews, B. M. Hooper, S. Whittingham, I. R. Mackay, and N. S. Stenhouse, "Association of autoantibodies with smoking, cardiovascular morbidity, and death in the Busselton population," The Lancet, vol. 2, no. 7832, pp. 754-758, 1973.

[112] T. Tuomi, M. Heliovaara, T. Palosuo, and K. Aho, "Smoking, lung function, and rheumatoid factors," Annals of the Rheumatic Diseases, vol. 49, no. 10, pp. 753-756, 1990.

[113] M. S. Wilson and T. A. Wynn, "Pulmonary fibrosis: pathogenesis, etiology and regulation," Mucosal Immunology, vol. 2, no. 2, pp. 103-121, 2009.

[114] S. C. L. Farhat, C. A. Silva, M. A. M. Orione, L. M. A. Campos, A. M. E. Sallum, and A. L. F. Braga, "Air pollution in autoimmune rheumatic diseases: a review," Autoimmunity Reviews, vol. 11, no. 1, pp. 14-21, 2011.

[115] S. A. Yousem, T. V. Colby, and C. B. Carrington, "Lung biopsy in rheumatoid arthritis," The American Review of Respiratory Disease, vol. 131, no. 5, pp. 770-777, 1985.

[116] A. Manzo, B. Vitolo, F. Humby et al., "Mature antigenexperienced $\mathrm{T}$ helper cells synthesize and secrete the B cell chemoattractant CXCL13 in the inflammatory environment of the rheumatoid joint," Arthritis and Rheumatism, vol. 58, no. 11, pp. 3377-3387, 2008.

[117] S. R. Atkins, C. Turesson, J. L. Myers et al., "Morphologic and quantitative assessment of CD20+ B cell infiltrates in rheumatoid arthritis-associated nonspecific interstitial pneumonia and usual interstitial pneumonia," Arthritis and Rheumatism, vol. 54, no. 2, pp. 635-641, 2006.
[118] C. Turesson, E. L. Matteson, T. V. Colby et al., "Increased CD4+ $\mathrm{T}$ cell infiltrates in rheumatoid arthritis-associated interstitial pneumonitis compared with idiopathic interstitial pneumonitis," Arthritis and Rheumatism, vol. 52, no. 1, pp. 73-79, 2005.

[119] Y. Nagasawa, T. Takada, T. Shimizu et al., "Inflammatory cells in lung disease associated with rheumatoid arthritis," Internal Medicine, vol. 48, no. 14, pp. 1209-1217, 2009.

[120] G. Hoser, J. Kawiak, J. Domagała-Kulawik, P. Kopiński, and W. Droszcz, "Flow cytometric evaluation of lymphocyte subpopulations in BALF of healthy smokers and nonsmokers," Folia Histochemica et Cytobiologica, vol. 37, no. 1, pp. 25-30, 1999.

[121] J. G. N. Garcia, H. L. James, S. Zinkgraf, M. B. Perlman, and B. A. Keogh, "Lower respiratory tract abnormalities in rheumatoid interstitial lung disease. Potential role of neutrophils in lung injury," The American Review of Respiratory Disease, vol. 136, no. 4, pp. 811-817, 1987.

[122] R. C. Keith, J. L. Powers, E. F. Redente et al., "A novel model of rheumatoid arthritis-associated interstitial lung disease in SKG mice," Experimental Lung Research, vol. 38, no. 2, pp. 55-66, 2012.

[123] K. Zhang, M. Gharaee-Kermani, B. McGarry, D. Remick, and S. H. Phan, "TNF- $\alpha$-mediated lung cytokine networking and eosinophil recruitment in pulmonary fibrosis," Journal of Immunology, vol. 158, no. 2, pp. 954-959, 1997.

[124] L. K. A. Lundblad, J. Thompson-Figueroa, T. Leclair et al., "Tumor necrosis factor- $\alpha$ overexpression in lung disease: a single cause behind a complex phenotype," The American Journal of Respiratory and Critical Care Medicine, vol. 171, no. 12, pp. 1363-1370, 2005.

[125] M. Vasakova, I. Striz, A. Slavcev et al., "Correlation of IL- $1 \alpha$ and IL-4 gene polymorphisms and clinical parameters in idiopathic pulmonary fibrosis," Scandinavian Journal of Immunology, vol. 65, no. 3, pp. 265-270, 2007.

[126] J. Rangel-Moreno, L. Hartson, C. Navarro, M. Gaxiola, M. Selman, and T. D. Randall, "Inducible bronchus-associated lymphoid tissue (iBALT) in patients with pulmonary complications of rheumatoid arthritis," Journal of Clinical Investigation, vol. 116, no. 12, pp. 3183-3194, 2006.

[127] C. Agostini and C. Gurrieri, "Chemokine/cytokine cocktail in idiopathic pulmonary fibrosis," Proceedings of the American Thoracic Society, vol. 3, no. 4, pp. 357-363, 2006.

[128] J. M. Vignaud, M. Allam, N. Martinet, M. Pech, F. Plenat, and Y. Martinet, "Presence of platelet-derived growth factor in normal and fibrotic lung is specifically associated with interstitial macrophages, while both interstitial macrophages and alveolar epithelial cells express the c-sis proto-oncogene," The American Journal of Respiratory Cell and Molecular Biology, vol. 5, no. 6, pp. 531-538, 1991.

[129] E. J. Battegay, E. W. Raines, T. Colbert, and R. Ross, “TNF- $\alpha$ stimulation of fibroblast proliferation: dependence on plateletderived growth factor (PDGF) secretion and alteration of PDGF receptor expression," Journal of Immunology, vol. 154, no. 11, pp. 6040-6047, 1995.

[130] A. Abdollahi, M. Li, G. Ping et al., "Inhibition of platelet-derived growth factor signaling attenuates pulmonary fibrosis," Journal of Experimental Medicine, vol. 201, no. 6, pp. 925-935, 2005.

[131] C. Ramos, M. Montaño, J. García-Alvarez et al., "Fibroblasts from idiopathic pulmonary fibrosis and normal lungs differ in growth rate, apoptosis, and tissue inhibitor of metalloproteinases expression," The American Journal of Respiratory Cell and Molecular Biology, vol. 24, no. 5, pp. 591-598, 2001. 
[132] T. R. Dunkern, D. Feurstein, G. A. Rossi, F. Sabatini, and A. Hatzelmann, "Inhibition of TGF- $\beta$ induced lung fibroblast to myofibroblast conversion by phosphodiesterase inhibiting drugs and activators of soluble guanylyl cyclase," European Journal of Pharmacology, vol. 572, no. 1, pp. 12-22, 2007.

[133] J. K. Dawson, H. E. Fewins, J. Desmond, M. P. Lynch, and D. R. Graham, "Fibrosing alveolitis in patients with rheumatoid arthritis as assessed by high resolution computed tomography, chest radiography, and pulmonary function tests," Thorax, vol. 56, no. 8, pp. 622-627, 2001.

[134] B. Wallaert, P. Y. Hatron, J. M. Grosbois, A. B. Tonnel, B. Devulder, and C. Voisin, "Subclinical pulmonary involvement in collagen-vascular diseases assessed by bronchoalveolar lavage. Relationship between alveolitis and subsequent changes in lung function," The American Review of Respiratory Disease, vol. 133, no. 4, pp. 574-580, 1986.

[135] F. Salaffi, P. Manganelli, M. Carotti, and S. Baldelli, "The differing patterns of subclinical pulmonary involvement in connective tissue diseases as shown by application of factor analysis," Clinical Rheumatology, vol. 19, no. 1, pp. 35-41, 2000.

[136] J. Biederer, A. Schnabel, C. Muhle, W. L. Gross, M. Heller, and M. Reuter, "Correlation between HRCT findings, pulmonary function tests and bronchoalveolar lavage cytology in interstitial lung disease associated with rheumatoid arthritis," European Radiology, vol. 14, no. 2, pp. 272-280, 2004.

[137] F. Kinoshita, H. Hamano, H. Harada et al., "Role of KL-6 in evaluating the disease severity of rheumatoid lung disease: comparison with HRCT," Respiratory Medicine, vol. 98, no. 11, pp. 1131-1137, 2004.

[138] T. Oyama, N. Kohno, A. Yokoyama et al., "Detection of interstitial pneumonitis in patients with rheumatoid arthritis by measuring circulating levels of KL-6, a human MUC1 mucin," Lung, vol. 175, no. 6, pp. 379-385, 1997.

[139] S. Horie, K. Nakada, S. Minota, and S. Kano, "High proliferative potential colony-forming cells (HPP-CFCs) in the peripheral blood of rheumatoid arthritis patients with interstitial lung disease," Scandinavian Journal of Rheumatology, vol. 32, no. 5, pp. 273-276, 2003.

[140] J. Fujita, N. Dobashi, Y. Ohtsuki et al., "Elevation of anticytokeratin 19 antibody in sera of the patients with idiopathic pulmonary fibrosis and pulmonary fibrosis associated with collagen vascular disorders," Lung, vol. 177, no. 5, pp. 311-319, 1999.

[141] K. Maniwa, F. Ogushi, K. Tani, Y. Ohmoto, M. Muraguchi, and S. Sone, "Increased incidence of autoantibodies to interleukin$1 \alpha$ in rheumatoid arthritis with interstitial lung disease," Respirology, vol. 5, no. 4, pp. 315-320, 2000.

[142] A. L. Mammen, "Dermatomyositis and polymyositis: clinical presentation, autoantibodies, and pathogenesis," Annals of the New York Academy of Sciences, vol. 1184, pp. 134-153, 2010.

[143] L. Cavagna, C. Fusetti, C. Montecucco, and R. Caporali, "Anticyclic citrullinated peptide antibodies as markers of erosive arthritis in antisynthetase syndrome," Journal of Rheumatology, vol. 37, no. 9, p. 1967, 2010.

[144] Y. Koreeda, I. Higashimoto, M. Yamamoto et al., "Clinical and pathological findings of interstitial lung disease patients with anti-aminoacyl-tRNA synthetase autoantibodies," Internal Medicine, vol. 49, no. 5, pp. 361-369, 2010.

[145] R. Stanciu, M. Guiguet, L. Musset et al., "Antisynthetase syndrome with anti-Jol antibodies in 48 patients: pulmonary involvement predicts disease-modifying antirheumatic drug use," Journal of Rheumatology, vol. 39, no. 9, pp. 1835-1839, 2012.
[146] K. Marzouk, L. Corate, S. Saleh, and O. P. Sharma, "EpsteinBarr-virus-induced interstitial lung disease," Current Opinion in Pulmonary Medicine, vol. 11, no. 5, pp. 456-460, 2005.

[147] C. A. Müller, H. Hebart, A. Roos, H. Roos, M. Steidle, and $\mathrm{H}$. Einsele, "Correlation of interstitial pneumonia with human cytomegalovirus-induced lung infection and graft-versus-host disease after bone marrow transplantation," Medical Microbiology and Immunology, vol. 184, no. 3, pp. 115-121, 1995.

[148] L. Cavagna and R. Caporali, "Therapeutic options in anti-Jol antisynthetase syndrome with interstitial lung disease," Arthritis Care and Research, vol. 65, no. 9, p. 1548, 2013.

[149] K. M. Antoniou, G. Margaritopoulos, F. Economidou, and N. M. Siafakas, "Pivotal clinical dilemmas in collagen vascular diseases associated with interstitial lung involvement," European Respiratory Journal, vol. 33, no. 4, pp. 882-896, 2009.

[150] C. Lamblin, C. Bergoin, T. Saelens, and B. Wallaert, "Interstitial lung diseases in collagen vascular diseases," European Respiratory Journal Supplement, vol. 18, no. 32, pp. 69-80, 2001.

[151] C. Kelly and V. Saravanan, "Treatment strategies for a rheumatoid arthritis patient with interstitial lung disease," Expert Opinion on Pharmacotherapy, vol. 9, no. 18, pp. 3221-3230, 2008.

[152] L. A. Saketkoo and L. R. Espinoza, "Rheumatoid arthritis interstitial lung disease: mycophenolate mofetil as an antifibrotic and disease-modifying antirheumatic drug," Archives of Internal Medicine, vol. 168, no. 15, pp. 1718-1719, 2008.

[153] M. P. E. Puttick, A. V. Klinkhoff, A. Chalmers, and D. N. Ostrow, "Treatment of progressive rheumatoid interstitial lung disease with cyclosporine," Journal of Rheumatology, vol. 22, no. 11, pp. 2163-2165, 1995.

[154] D. Ogawa, H. Hashimoto, J. Wada et al., "Successful use of cyclosporin A for the treatment of acute interstitial pneumonitis associated with rheumatoid arthritis," Rheumatology, vol. 39, no. 12, pp. 1422-1424, 2000.

[155] H. K. Chang, W. Park, and D. S. Ryu, "Successful treatment of progressive rheumatoid interstitial lung disease with cyclosporine: a case report," Journal of Korean medical science, vol. 17, no. 2, pp. 270-273, 2002.

[156] Z. M. Metafratzi, A. N. Georgiadis, C. V. Ioannidou et al., "Pulmonary involvement in patients with early rheumatoid arthritis," Scandinavian Journal of Rheumatology, vol. 36, no. 5, pp. 338-344, 2007.

[157] J. Rojas-Serrano, E. González-Velásquez, M. Mejía, A. SánchezRodríguez, and G. Carrillo, "Interstitial lung disease related to rheumatoid arthritis: evolution after treatment," Reumatología Clínica, vol. 8, no. 2, pp. 68-71, 2012.

[158] M. Mohr and A. M. Jacobi, "Interstitial lung disease in rheumatoid arthritis: response to IL-6R blockade," Scandinavian Journal of Rheumatology, vol. 40, no. 5, pp. 400-401, 2011.

[159] A. V. Hadjinicolaou, M. K. Nisar, S. Bhagat, H. Parfrey, E. R. Chilvers, and A. J. K. Östör, "Non-infectious pulmonary complications of newer biological agents for rheumatic diseasesa systematic literature review," Rheumatology, vol. 50, no. 12, Article ID ker289, pp. 2297-2305, 2011.

[160] S. Y. Kawashiri, A. Kawakami, N. Sakamoto, Y. Ishimatsu, and K. Eguchi, "A fatal case of acute exacerbation of interstitial lung disease in a patient with rheumatoid arthritis during treatment with tocilizumab," Rheumatology International, vol. 32, no. 12, pp. 4023-4026, 2012. 


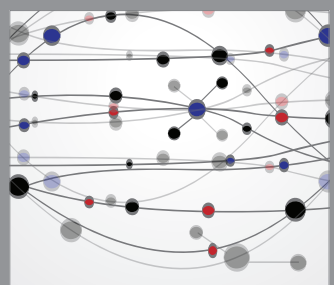

The Scientific World Journal
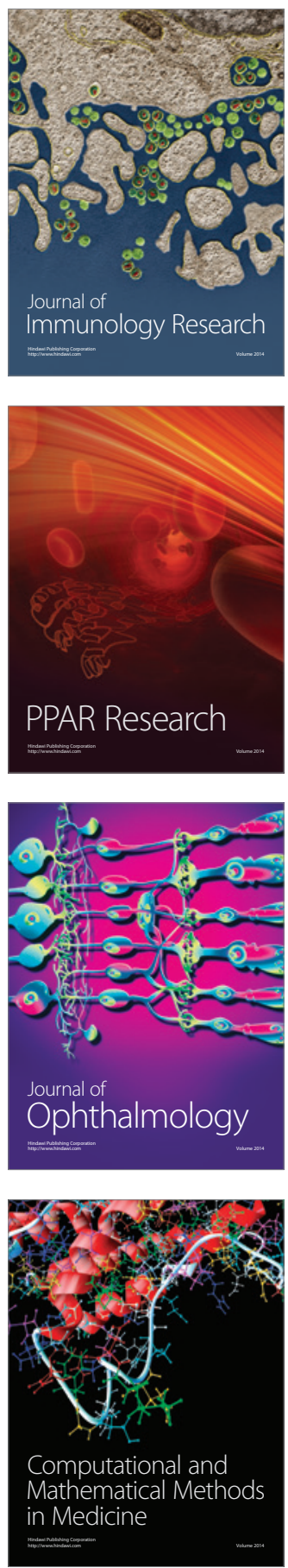

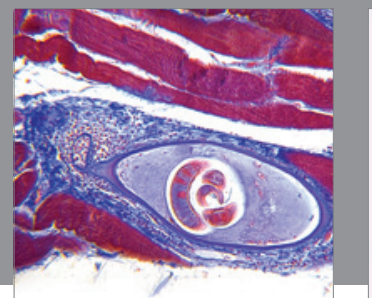

Gastroenterology

Research and Practice
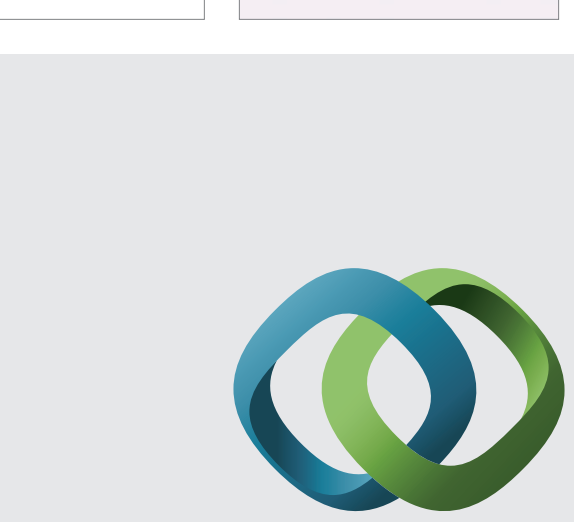

\section{Hindawi}

Submit your manuscripts at

http://www.hindawi.com
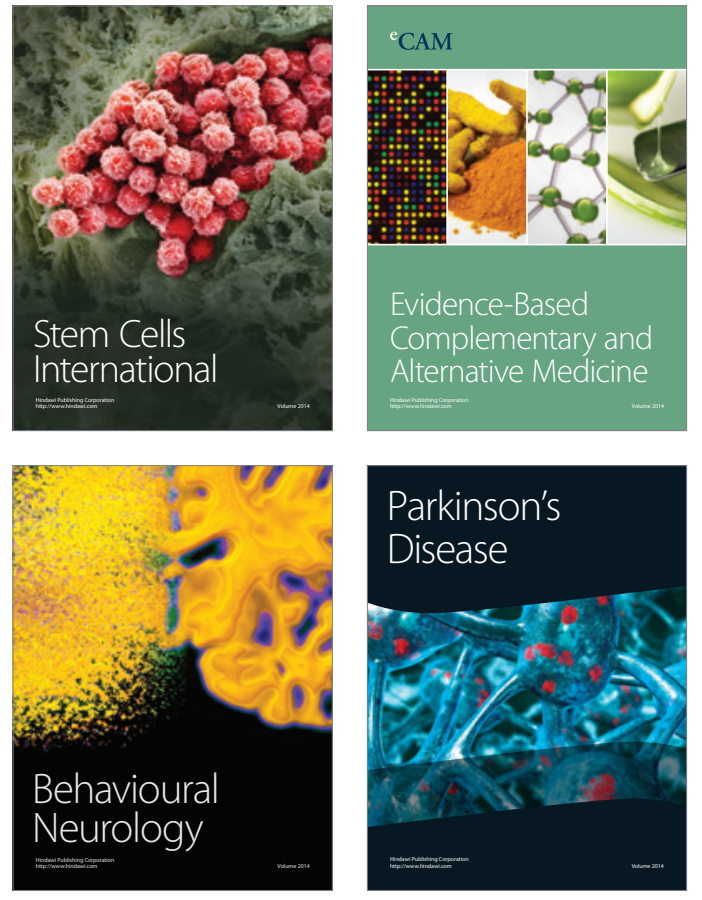
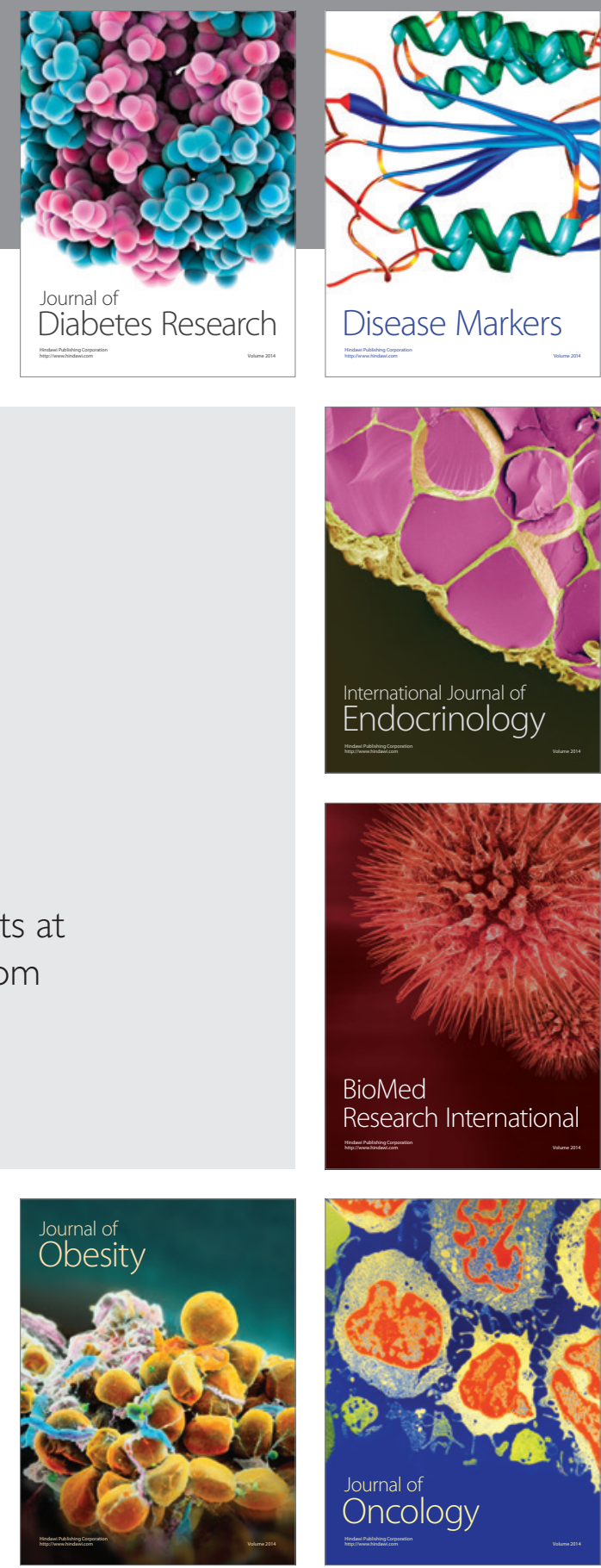

Disease Markers
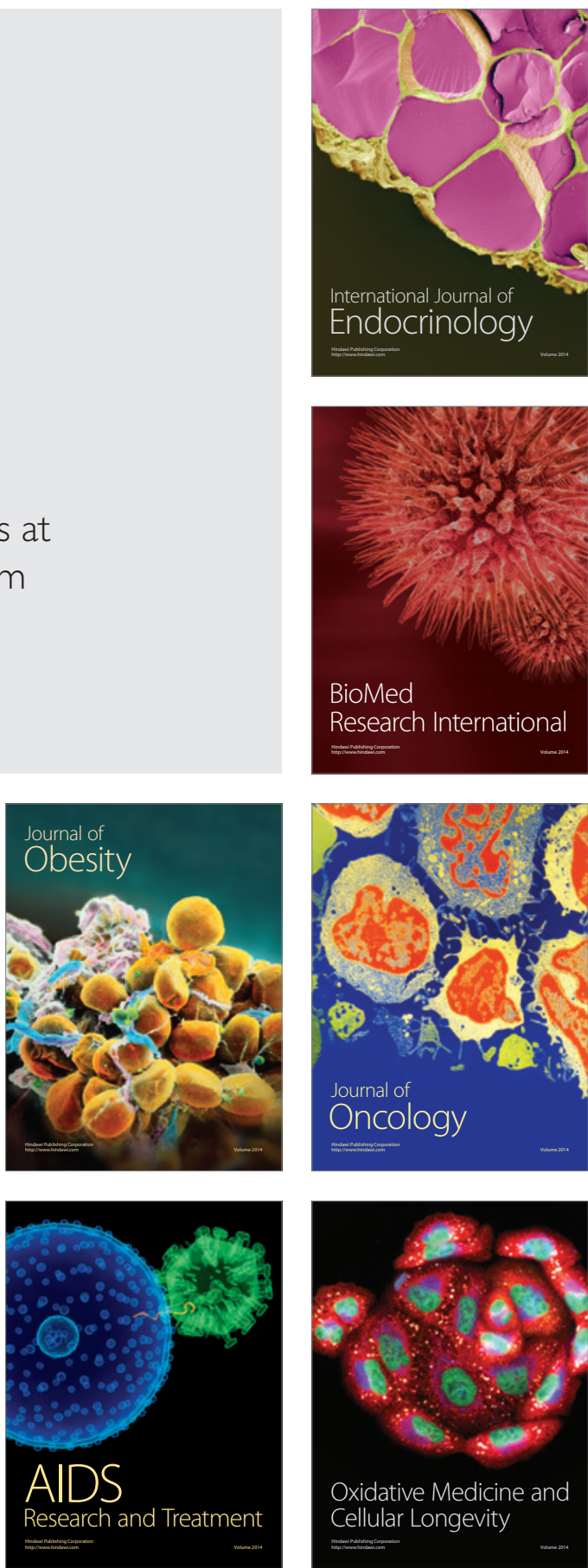